\title{
$X$-ray diffraction line profile analysis for defect study in Zr-2.5\% Nb material
}

\author{
K KAPOOR*, D LAHIRI, S V R RAO, T SANYAL and B P KASHYAP \\ Advanced Materials Characterization Laboratory, Nuclear Fuel Complex, Hyderabad 500 062, India \\ ${ }^{\dagger}$ Metallurgical Engineering and Materials Science Department, Indian Institute of Technology, \\ Mumbai 400 076, India
}

MS received 17 January 2003; revised 4 November 2003

\begin{abstract}
The microstructure characterization by $\mathrm{X}$-ray line profile analysis is possible for determination of dislocation density, micro-strain within grains due to dislocation and average coherent domain size (subgrain) within the grain. This study presents the $\mathrm{X}$-ray diffraction peaks shape analysis and their broadening with different thermal treatments in $\mathrm{Zr}-2.5 \% \mathrm{Nb}$ pressure tube material. The peak shape is analysed using Fourier transformation and information about coherent domain size, micro-strain and dislocation density could be obtained from the Fourier coefficients of the peak. Analysis of broadening of the peaks by integral breadth method also gives the coherent domain size, dislocation density and micro-strain present in the material. The results from the $\mathrm{X}$-ray techniques are comparable to those obtained from direct observation of transmission electron microscopy. The measured yield strength increases with dislocation density. An empirical relationship is obtained for the yield strength from the dislocation density of the material. The measured strength is in agreement with the one calculated from dislocation density.
\end{abstract}

Keywords. XRD; line profile analysis; coherent domain size; microstrain; dislocation density; $\mathrm{Zr}-\mathbf{2} \cdot \mathbf{5 \%} \mathrm{Nb}$.

\section{Introduction}

1.1 Microstructure analysis using $X$-ray diffraction line profile analysis

The diffraction pattern obtained from a metallic sample gives information about imperfections in the material i.e. dislocations, small crystallite (domain) size, microstrains within the grains due to dislocations and stacking faults. The X-ray diffraction (XRD) peak is broadened due to small crystallite size and strain due to dislocations and stacking faults. The analysis of the shape of the peaks for obtaining information about the material is referred to as line profile analysis (LPA).

Dislocation density $(\rho)$ is an important material property, which gives the length of the dislocations present per unit volume $\left(\mathrm{m} / \mathrm{m}^{3}\right)$ in the material. It has a strong influence on out-of-pile and in-pile properties of critical clad and structural materials for pressurized heavy water nuclear reactors. X-ray line broadening technique has been used widely to estimate the dislocation density. But use of this technique requires careful experimentation, sample preparation and calculations.

*Author for correspondence
The line profiles of the reflections of various planes during X-ray diffraction are characteristic of the state of the material. The shapes of line profiles are also affected by instrument and sample shape, which is referred to as instrumental broadening. This instrumental broadening needs to be eliminated to obtain broadening exclusively due to metallurgical effects. Once such data is obtained, estimation of coherent domain size, micro strains within these domains, density of dislocation, stacking fault probability etc can be done. Coherent domain size $(D)$ is the size of coherently diffracting region within a grain, representing fault free region between dislocations (of the order of $100-1000 \AA$ ), higher the $\rho$ lower the $D$. Within this region, due to dislocations, micro strain $(\varepsilon)$ is present between the atomic planes (of the order of $10^{-3}$ ). The observed broadening in X-ray line profiles is due to the $D$ and $\varepsilon$ present in the material. Once the $D$ and $\varepsilon$ are determined from the broadening, the dislocation density can be estimated.

There are two basic techniques of X-ray line profile analysis: (i) Fourier space technique under which Fourier analysis (Warren 1968) also forms a part, and (ii) real space techniques like (a) integral breadth (Wagner and Aqua 1964), (b) variance analysis (Wilson 1962) and (c) peakfitting methods (Keijser et al 1982). It has been shown that each of the above techniques leads to similar results for domain size, dislocation density etc. 
Peak fitting methods are based on the analysis of the full width of the line profile at half of the maximum intensity and the integral breadth that can be easily determined from the peak profile. It is well established that profile arising due to size broadening are approximately Cauchy and due to lattice strain broadening is nearly Gaussian in nature. By fitting the diffraction peak profile with Voigt/ pseudo-Voigt function the Cauchy and Gauss contributions ( $\beta_{\mathrm{C}}$ and $\beta_{\mathrm{G}}$, respectively) could be determined. Alternatively, $\beta_{\mathrm{C}}$ and $\beta_{\mathrm{G}}$ of a peak are determined from the value of integral breadth and full width half maxima of the peak using well established relationships (Keijser et al 1982). Coherent domain size and lattice strain are calculated from $\beta_{\mathrm{C}}$ and $\beta_{\mathrm{G}}$ of a peak.

In the present study, one Fourier space method (Fourier analysis) and one real space method (integral breadth method), has been used for analysis of results to get a comparative view of two basic techniques. In the integral breadth method the peaks that are affected by stacking fault are also included to give overall dislocation density including the stacking fault concentration. On the other hand, Fourier analysis gives separate estimation of stacking fault concentration in addition to $\rho, D$ and $\varepsilon$. The correction for instrumental broadening is most important step in the estimation of material properties from line profile analysis. The results from the two techniques have been compared with each other with different sample conditions. The direct observation transmission electron microscopy (TEM) techniques which are also used for these measurements are extremely time consuming and expensive. The results of the $\mathrm{X}$-rays are in good agreement with the TEM.

\subsection{Material}

The present study is carried out on $\mathrm{Zr}-2 \cdot 5 \mathrm{wt} \% \mathrm{Nb}$ (hereafter called $\mathrm{Zr}-2.5 \mathrm{Nb}$ ) pressure tube material for pressurized heavy water reactor (PHWR). Zirconium base alloys are used in nuclear reactors for their low neutron absorption cross-section, good elevated temperature mechanical strength, low irradiation creep and high corrosion resistance in reactor atmosphere. $\mathrm{Zr}-2.5 \mathrm{Nb}$, currently used for pressure tubes, has replaced Zircaloy-2 due to its better physical and mechanical properties leading to increased life in the reactor. The chemical composition of the alloy is given in table 1 .

$\mathrm{Zr}-2.5 \mathrm{Nb}$ is a two-phase material with major $\alpha$ (HCP) phase with fine network of $\beta$ phase at grain-boundaries. The $\alpha$ phase is elongated lamellar shaped having aspect ratio of $1: 5: 10$ (thickness : width: length). Due to cold work, dislocations network is formed in $\alpha$ phase. Initially the $\beta$ phase forms a network around $\alpha$ phase and with thermo-mechanical processing the $\beta$ network is broken. The TEM micrograph of the material in cold worked and stress relieved condition is presented in figure 1 . The material for the study was taken in cold worked condition and was given heat treatments to modify the dislocation network in the $\alpha$ phase.

The study has been carried out on the material in four different thermomechanical conditions (table 2). The dislocation density measurements were done to the samples with following conditions. The measured dislocation density was correlated to yield strength (YS) measured by tensile testing at $573 \mathrm{~K}$ for the material in those conditions. This temperature was selected as the operation temperature for this component in the reactor at $573 \mathrm{~K}$.

\section{Experimental}

For diffraction profile data generation, Rigaku Dmax 2000 $\mathrm{X}$-ray diffractometer fitted with a horizontal goniometer was used.

Table 1. Chemical specification of the studied material.

\begin{tabular}{ll}
\hline Element & Composition \\
\hline Niobium (\%) & $2 \cdot 4-2 \cdot 8$ \\
Oxygen (ppm) & $900-1300$ \\
Iron (ppm) & $650 \max$ \\
Chromium (ppm) & $200 \max$ \\
Tin (ppm) & $100 \max$ \\
Copper (ppm) & $30 \max$ \\
Nitrogen (ppm) & $65 \max$ \\
Hydrogen (ppm) & $5 \max$ \\
Chlorine (ppm) & $0 \cdot 5 \max$ \\
Phosphorous (ppm) & $10 \max$ \\
Zirconium & Balance \\
\hline
\end{tabular}

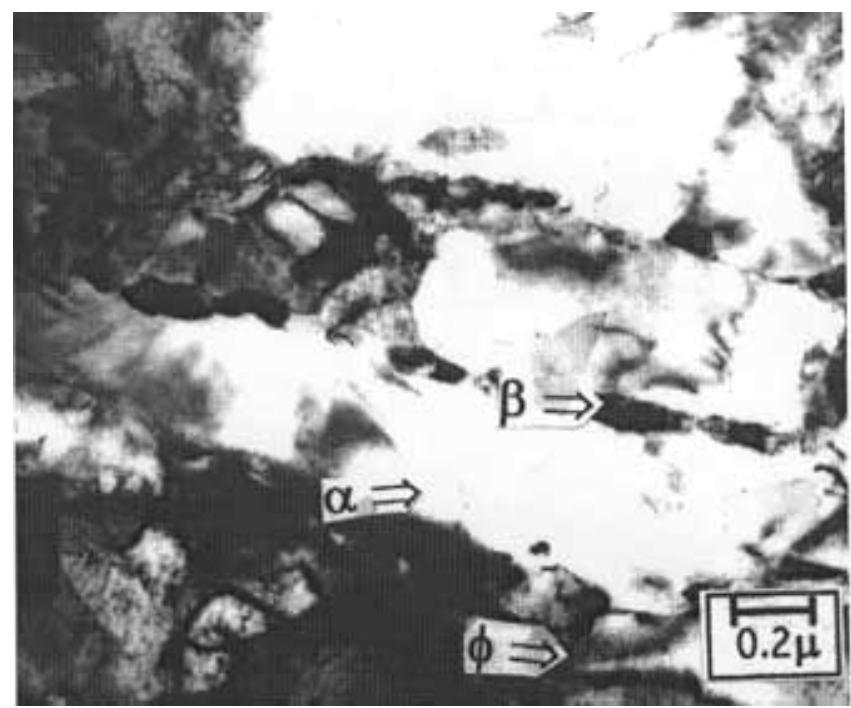

Figure 1. TEM micrograph for the $\mathrm{Zr}-2.5 \mathrm{Nb}$ pressure tube material in cold worked and stress relieved condition showing the high dislocation network within $\alpha$ grains and $\beta$ phase at the grain boundary. 
For sample preparation, two specimens with dimensions $12 \mathrm{~mm}$ (width) $\times 25 \mathrm{~mm}$ (length), were taken from a pressure tube. The length direction was parallel to the tube rolling direction and the tube normal (thickness) direction was parallel to the sample surface normal. To prepare the specimen for reflection geometry, the outer surface of the tube was ground flat, polished mechanically and etched. The sample was irradiated with X-rays falling on this surface. The sample was stationary (no sample spinning) and all the samples were positioned identically for X-ray diffraction measurement, as the profile is sensitive to these parameters. The raw data were processed for smoothening, background elimination etc. The instrument settings used for obtaining peak data are given in table 3 .

Thin foils for TEM were prepared by electropolishing using double-jet thinning in a solution of $6 \%$ sulphuric acid in methanol maintained at $223 \mathrm{~K}$. Thin foils were examined in Philips PEM 430T (Philips FEI Electron Optics, Eindhoven, Netherlands) TEM operating at $300 \mathrm{kV}$.

Mechanical tests were carried out at elevated temperature as per ASTM E21 in ZWICK Universal Testing Machine with high temperature testing attachments (model no: 1476). The testing was carried out at $573 \mathrm{~K}$.

\section{Theory of analysis and results}

The raw data obtained for the six peaks of each of the samples is given in table 4.

Table 2. Different thermomechanical conditions of the material under study.

\begin{tabular}{|c|c|}
\hline $\begin{array}{l}\text { Sample } \\
\text { no. }\end{array}$ & Sample condition \\
\hline 1 & As pilgered \\
\hline 2 & $\begin{array}{l}\text { Pilgered + stress relieved }\left(400^{\circ} \mathrm{C}, 24 \mathrm{~h}\right) \text {, } \\
4 \text { different samples, } 2 \text { a to d, were evaluated for } \\
\text { integral breadth calculation }\end{array}$ \\
\hline 3 & $\begin{array}{l}\text { Pilgered }+\mathrm{SR}\left(400^{\circ} \mathrm{C}, 24 \mathrm{~h}\right)+\text { annealed } \\
\quad\left(450^{\circ} \mathrm{C}, 3 \mathrm{~h}\right)\end{array}$ \\
\hline 4 & $\begin{array}{l}\text { Pilgered + SR }\left(400^{\circ} \mathrm{C}, 24 \mathrm{~h}\right)+\text { annealed } \\
\left(500^{\circ} \mathrm{C}, 3 \mathrm{~h}\right)\end{array}$ \\
\hline
\end{tabular}

Table 3. Settings used for obtaining peak data.

\begin{tabular}{ll}
\hline Radiation & $\mathrm{CuK}_{\alpha}$ \\
Scan rate & $0 \cdot 1^{\circ}$ per min. \\
Step size & $0 \cdot 002^{\circ}$ \\
$K \alpha / K \beta$ separation & Using curved crystal monochromator \\
& placed at the receiving end \\
Background correction & Averaging at the end. \\
$K \alpha 2$ separation & Using software with $\alpha 1 / \alpha 2$ ratio as $0 \cdot 5$ \\
Sample rotation & No (Stationary) \\
\hline
\end{tabular}

\subsection{Fourier analysis}

In the Fourier analysis the line breadth is corrected for instrumental broadening using Stoke's (1948) correction. According to the Stokes correction method, the observed intensity across a line is related to the distribution due to instrumental broadening as well as small particle size by the equation

$$
h(x)=\int_{-\alpha}^{\alpha} f(y) g(x-y) \mathrm{d} y
$$

where $f(x)$ represents the peak with broadening due to particle size only and without any effect of instrumental broadening, $g(x)$ is from the specimen giving negligible broadening in itself and the total broadening is instrumental only, $h(x)$ the observed peak containing both instrumental and material effect. Knowing $h(x)$ and $g(x)$, the $f(x)$ and Fourier coefficients of $f(x)$ can be calculated by Fourier analysis. The real and imaginary Fourier coefficients of $g(x)$ are calculated using the following equations

$$
\begin{aligned}
& G_{\mathrm{r}}(t)=\frac{1}{a} \int_{-a / 2}^{a / 2} g(x) \cos (2 \pi x t / a) \mathrm{d} x, \\
& G_{\mathrm{i}}(t)=\frac{1}{a} \int_{-a / 2}^{a / 2} g(x) \sin (2 \pi x t / a) \mathrm{d} x,
\end{aligned}
$$

where $a$ is the total number of data points.

Similar equations are used for calculation of $H_{\mathrm{r}}(t)$ and $H_{\mathrm{i}}(t)$ also. Once these are known, the fourier coefficient for $f(x)$ is also determined as follows

$$
\begin{aligned}
& F_{\mathrm{r}}(t)=\frac{H_{\mathrm{r}}(t) G_{\mathrm{r}}(t)+H_{\mathrm{i}}(t) G_{\mathrm{i}}(t)}{G_{\mathrm{r}}^{2}+G_{\mathrm{i}}^{2}}, \\
& F_{\mathrm{i}}(t)=\frac{H_{\mathrm{i}}(t) G_{\mathrm{r}}(t)-H_{\mathrm{r}}(t) G_{\mathrm{i}}(t)}{G_{\mathrm{r}}^{2}+G_{\mathrm{i}}^{2}},
\end{aligned}
$$

Now, $f(x)$ can be calculated from $F_{\mathrm{r}}(t)$ and $F_{\mathrm{i}}(t)$ as

$$
f(x)=\int_{0}^{t} F_{\mathrm{r}}(t) \cos (2 \pi x t / a) \mathrm{d} t+\int_{0}^{t} F_{\mathrm{i}}(t) \sin (2 \pi x t / a) \mathrm{d} t
$$

For calculation of the Fourier coefficients from the peak data and also the inverse transformation of the Fourier coefficients to peak function, the cubic spline method for numerical integration has been used (Einarsson 1972). 
Table 4. X-ray peak data.

\begin{tabular}{|c|c|c|c|c|c|c|c|}
\hline & $H K L$ & Peak top & Gravity $(\mathrm{P})$ & Max. int & Integ. int & FWHM & Integ. (W) \\
\hline \multicolumn{8}{|c|}{ Sample no. 1 (cold pilgered) } \\
\hline 1 & $00 \cdot 2$ & $34 \cdot 54$ & $34 \cdot 53$ & 1217 & $496 \cdot 45$ & $0 \cdot 355$ & $0 \cdot 408$ \\
\hline 2 & $11 \cdot 0$ & $56 \cdot 53$ & $56 \cdot 52$ & 2092 & $1152 \cdot 33$ & $0 \cdot 482$ & $0 \cdot 551$ \\
\hline 3 & $10 \cdot 3$ & $63 \cdot 32$ & $63 \cdot 35$ & 280 & $182 \cdot 73$ & $0 \cdot 569$ & $0 \cdot 652$ \\
\hline 4 & $11 \cdot 2$ & $68 \cdot 18$ & $68 \cdot 20$ & 1817 & $1033 \cdot 27$ & $0 \cdot 506$ & $0 \cdot 569$ \\
\hline 5 & $21 \cdot 1$ & $95 \cdot 52$ & $95 \cdot 54$ & 89 & $87 \cdot 19$ & $0 \cdot 883$ & $0 \cdot 982$ \\
\hline 6 & $11 \cdot 4$ & $99 \cdot 75$ & $99 \cdot 78$ & 303 & $266 \cdot 88$ & $0 \cdot 838$ & $0 \cdot 882$ \\
\hline \multicolumn{8}{|c|}{ Sample no. 2 a (Heat treated at $400^{\circ} \mathrm{C}$ ) } \\
\hline 1 & $00 \cdot 2$ & $34 \cdot 11$ & $34 \cdot 07$ & 719 & $189 \cdot 15$ & $0 \cdot 220$ & $0 \cdot 263$ \\
\hline 2 & $11 \cdot 0$ & $56 \cdot 26$ & $56 \cdot 25$ & 1302 & $166 \cdot 45$ & $0 \cdot 296$ & $0 \cdot 358$ \\
\hline 3 & $10 \cdot 3$ & 62.90 & 62.91 & 171 & $54 \cdot 82$ & $0 \cdot 286$ & $0 \cdot 350$ \\
\hline 4 & $11 \cdot 2$ & $67 \cdot 86$ & $67 \cdot 87$ & 1359 & $478 \cdot 10$ & $0 \cdot 327$ & $0 \cdot 434$ \\
\hline 5 & $21 \cdot 1$ & $95 \cdot 51$ & $95 \cdot 57$ & 106 & $60 \cdot 27$ & $0 \cdot 425$ & 0.570 \\
\hline 6 & $11 \cdot 4$ & $99 \cdot 37$ & $99 \cdot 35$ & 320 & $99 \cdot 80$ & $0 \cdot 307$ & $0 \cdot 591$ \\
\hline \multicolumn{8}{|c|}{ Sample no. $2 \mathrm{~b}\left(\right.$ Heat treated at $\left.400^{\circ} \mathrm{C}\right)$} \\
\hline 1 & $00 \cdot 2$ & $34 \cdot 18$ & $34 \cdot 13$ & 808 & $213 \cdot 08$ & $0 \cdot 212$ & $0 \cdot 264$ \\
\hline 2 & $11 \cdot 0$ & $56 \cdot 32$ & $56 \cdot 31$ & 1567 & $536 \cdot 86$ & $0 \cdot 279$ & $0 \cdot 343$ \\
\hline 3 & $10 \cdot 3$ & $62 \cdot 95$ & $62 \cdot 92$ & 249 & $93 \cdot 62$ & $0 \cdot 300$ & $0 \cdot 377$ \\
\hline 4 & $11 \cdot 2$ & $67 \cdot 92$ & $67 \cdot 90$ & 1707 & $716 \cdot 83$ & $0 \cdot 327$ & $0 \cdot 420$ \\
\hline 5 & $21 \cdot 1$ & $95 \cdot 56$ & $95 \cdot 59$ & 143 & $86 \cdot 86$ & $0 \cdot 431$ & $0 \cdot 609$ \\
\hline 6 & $11 \cdot 4$ & $99 \cdot 40$ & $99 \cdot 40$ & 527 & $314 \cdot 62$ & $0 \cdot 480$ & $0 \cdot 597$ \\
\hline \multicolumn{8}{|c|}{ Sample no. $2 \mathrm{c}\left(\right.$ Heat treated at $\left.400^{\circ} \mathrm{C}\right)$} \\
\hline 1 & $00 \cdot 2$ & $34 \cdot 23$ & $34 \cdot 18$ & 1152 & $307 \cdot 76$ & $0 \cdot 217$ & $0 \cdot 267$ \\
\hline 2 & $11 \cdot 0$ & $56 \cdot 38$ & $56 \cdot 38$ & 1680 & $540 \cdot 04$ & $0 \cdot 255$ & $0 \cdot 322$ \\
\hline 3 & $10 \cdot 3$ & $63 \cdot 02$ & $62 \cdot 98$ & 367 & $136 \cdot 85$ & $0 \cdot 286$ & $0 \cdot 373$ \\
\hline 4 & $11 \cdot 2$ & 67.99 & $67 \cdot 97$ & 1819 & $738 \cdot 77$ & $0 \cdot 318$ & $0 \cdot 406$ \\
\hline 5 & $21 \cdot 1$ & $95 \cdot 62$ & $95 \cdot 62$ & 234 & $126 \cdot 58$ & $0 \cdot 452$ & $0 \cdot 540$ \\
\hline 6 & $11 \cdot 4$ & $99 \cdot 47$ & $99 \cdot 46$ & 580 & $348 \cdot 72$ & $0 \cdot 483$ & $0 \cdot 601$ \\
\hline \multicolumn{8}{|c|}{ Sample no. $2 \mathrm{~d}\left(\right.$ Heat treated at $\left.400^{\circ} \mathrm{C}\right)$} \\
\hline 1 & $00 \cdot 2$ & $34 \cdot 10$ & $34 \cdot 04$ & 653 & 193.79 & $0 \cdot 247$ & $0 \cdot 297$ \\
\hline 2 & $11 \cdot 0$ & $56 \cdot 26$ & $56 \cdot 25$ & 1001 & $351 \cdot 38$ & $0 \cdot 289$ & $0 \cdot 351$ \\
\hline 3 & $10 \cdot 3$ & $62 \cdot 86$ & $62 \cdot 89$ & 215 & $88 \cdot 14$ & $0 \cdot 315$ & $0 \cdot 410$ \\
\hline 4 & $11 \cdot 2$ & $67 \cdot 87$ & $67 \cdot 86$ & 1241 & $542 \cdot 64$ & $0 \cdot 339$ & $0 \cdot 437$ \\
\hline 5 & $21 \cdot 1$ & $95 \cdot 52$ & $95 \cdot 54$ & 179 & $94 \cdot 11$ & $0 \cdot 430$ & $0 \cdot 525$ \\
\hline 6 & $11 \cdot 4$ & $99 \cdot 36$ & $99 \cdot 36$ & 475 & $283 \cdot 60$ & $0 \cdot 493$ & $0 \cdot 598$ \\
\hline \multicolumn{8}{|c|}{ Sample no. 3 (Heat treated at $450^{\circ} \mathrm{C}$ ) } \\
\hline 1 & $00 \cdot 2$ & $34 \cdot 24$ & $34 \cdot 20$ & 739 & $172 \cdot 33$ & $0 \cdot 191$ & $0 \cdot 233$ \\
\hline 2 & $11 \cdot 0$ & $56 \cdot 39$ & $56 \cdot 37$ & 2127 & $644 \cdot 14$ & $0 \cdot 241$ & $0 \cdot 303$ \\
\hline 3 & $10 \cdot 3$ & $63 \cdot 01$ & $62 \cdot 98$ & 464 & $143 \cdot 65$ & $0 \cdot 242$ & $0 \cdot 309$ \\
\hline 4 & $11 \cdot 2$ & $67 \cdot 99$ & $67 \cdot 98$ & 2252 & $812 \cdot 86$ & $0 \cdot 278$ & $0 \cdot 361$ \\
\hline 5 & $21 \cdot 1$ & $95 \cdot 63$ & $95 \cdot 66$ & 228 & $104 \cdot 43$ & $0 \cdot 358$ & $0 \cdot 459$ \\
\hline 6 & $11 \cdot 4$ & $99 \cdot 46$ & $99 \cdot 45$ & 737 & 358.75 & $0 \cdot 390$ & $0 \cdot 487$ \\
\hline \multicolumn{8}{|c|}{ Sample no. 4 (Heat treated at $\left.500^{\circ} \mathrm{C}\right)$} \\
\hline 1 & $00 \cdot 2$ & $34 \cdot 63$ & $34 \cdot 61$ & 2652 & $548 \cdot 25$ & $0 \cdot 165$ & $0 \cdot 207$ \\
\hline 2 & $11 \cdot 0$ & $56 \cdot 75$ & $56 \cdot 73$ & 4843 & $1290 \cdot 66$ & $0 \cdot 213$ & $0 \cdot 267$ \\
\hline 3 & $10 \cdot 3$ & $63 \cdot 36$ & $63 \cdot 36$ & 762 & $197 \cdot 55$ & $0 \cdot 206$ & $0 \cdot 259$ \\
\hline 4 & $11 \cdot 2$ & $68 \cdot 32$ & $68 \cdot 32$ & 4775 & $1470 \cdot 86$ & $0 \cdot 242$ & $0 \cdot 308$ \\
\hline 5 & $21 \cdot 1$ & $95 \cdot 89$ & $95 \cdot 89$ & 346 & $150 \cdot 02$ & $0 \cdot 335$ & 0.434 \\
\hline 6 & $11 \cdot 4$ & 99.67 & 99.67 & 1099 & 451.79 & $0 \cdot 340$ & $0 \cdot 411$ \\
\hline
\end{tabular}

Figure 2 shows the effect of Stokes correction of instrumental broadening on the diffraction peak for this material. The $h(x), g(x)$ and $f(x)$ peaks (11.0) are superimposed. $K \alpha_{1}$ and $K \alpha_{2}$ separation is clearly visible in $g(x)$. In the $f(x)$ peak, derived after instrumental broadening correction, instrumentational broadening as well as the contribution from $K \alpha_{2}$ has been subtracted and so, the peak becomes sharper. It may be observed that the back half of the $h(x)$ peak which includes the contribution of $K \alpha_{2}$ is modified in the $f(x)$ curve while the front half is similar. 
The profile of the peak, corrected for instrumental broadening using the Stoke's correction mentioned above, can be expressed in terms of Fourier series (Chatterjee and Sengupta 1974). By considering each reflection of hexagonal close packed $(h c p)$ structure $\left(H K \cdot L_{0}\right)$ as a $\left(00 l^{\prime}\right)$ reflection in terms of orthorhombic axes, the Fourier series in terms of a position in reciprocal space is expressed as

$$
P_{2 \theta}^{\prime}=k^{\prime} \sum A_{\mathrm{L}}^{\mathrm{S}} A_{\mathrm{L}}^{\mathrm{D}} \cos 2 \pi n\left(h_{3}^{\prime}-l^{\prime}\right),
$$

where $h_{3}^{\prime}-l^{\prime}=2\left|a_{3}^{\prime}\right|\left(\sin \theta-\sin \theta_{0}\right) / \lambda$ and $\left|a_{3}^{\prime}\right|$ is a fictitious distance chosen to correspond to the $\sin \theta$ interval within which the peak is expressed as a Fourier series. $\theta_{0}$ refers to the peak maxima position and $\theta$ the independent variable for the peak-curve function. $A_{\mathrm{L}}^{\mathrm{S}}$ and $A_{\mathrm{L}}^{\mathrm{D}}$ represent the size and distortion coefficients, respectively and $A_{\mathrm{L}}^{\mathrm{S}}$ includes the effect of both domain size and faulting. The distortion coefficient can be expressed as

$$
A_{\mathrm{L}}^{\mathrm{D}}=\exp \left(-2 \pi^{2} L^{2}\left\langle\varepsilon_{\mathrm{L}}^{2}\right\rangle / d^{2}\right)
$$

where $L=n\left|a_{3}^{\prime}\right|$ which has a significance of a distance normal to the reflecting planes, $\left\langle\varepsilon_{\mathrm{L}}^{2}\right\rangle$ the mean square strain and $d$ the interplanar spacing of the reflecting planes.

The separation of distortion and size coefficients, $A_{\mathrm{L}}^{\mathrm{D}}$ and $A_{\mathrm{L}}^{\mathrm{D}}$, is done by $\log$ plot of $A_{\mathrm{L}}=A_{\mathrm{L}}^{\mathrm{D}} \cdot A_{\mathrm{L}}^{\mathrm{S}}$ against $1 / d^{2}$ using (8). The intercept yields $A_{\mathrm{L}}^{\mathrm{S}}$ and the slope gives $A_{\mathrm{L}}^{\mathrm{D}}$. Slope of the plots $A_{\mathrm{L}}^{\mathrm{S}}$ vs $L$ gives the domain size normal to the reflecting planes $(D)$,

$$
-\left(\mathrm{d} A_{\mathrm{L}}^{\mathrm{S}} / \mathrm{d} L\right)_{0}=1 / D \quad \text { for } H-K=3 n .
$$

Figure 3 represents the $A_{\mathrm{L}}$ vs $L$ plots for three $H-K=3 n$ peaks (where $H$ and $K$ are the Miller indices for the plane of diffraction and $n$ is an integer number) of cold worked stress relieved and annealed $\left(450^{\circ} \mathrm{C}, 3 \mathrm{~h}\right)$ samples after instrumental broadening correction. The $\ln \left(A_{\mathrm{L}}\right)$ vs $1 / d^{2}$ plots for the same sample with the same three peaks are

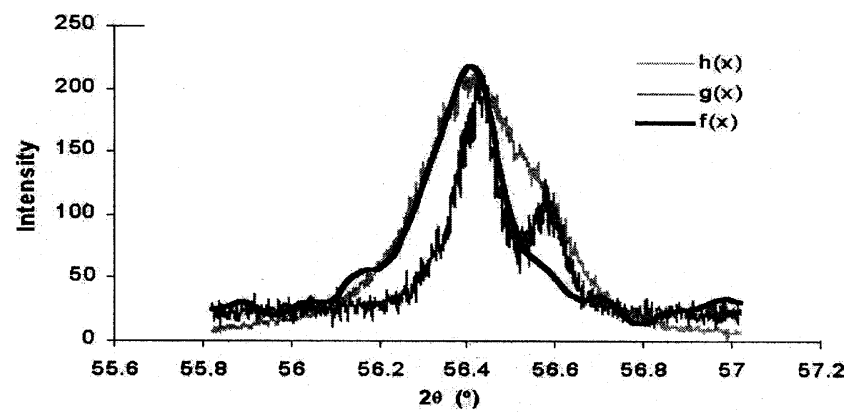

Figure 2. XRD peaks of (11.0) plane for pilgered + stress relieved + annealed $\left(450^{\circ} \mathrm{C}, 3 \mathrm{~h}\right)$ sample as obtained $[h(x)]$, with only instrumental broadening $[g(x)]$ and the derived one without instrumental broadening $[f(x)]$. shown in figure 4 for different $L$ values. The slope of the curves gives the value of $\ln \left(A_{\mathrm{L}}^{\mathrm{D}}\right)$, from which the microstrain, $\varepsilon_{\mathrm{L}}$, is calculated with respect to $L$ using (8). The intercept of the plots in figure 4 gives $\ln \left(A_{\mathrm{L}}^{\mathrm{S}}\right)$. The $A_{\mathrm{L}}^{\mathrm{S}}$ vs $L$ curve is shown in figure 5. Coherent domain size, $D$, is determined from the initial slope of this curve using (9).

Dislocation density can be calculated from $D$ and $\varepsilon_{\mathrm{L}}$ using following formulae

$$
\rho_{\mathrm{D}}=3 \eta / D^{2} \quad \eta=1,
$$

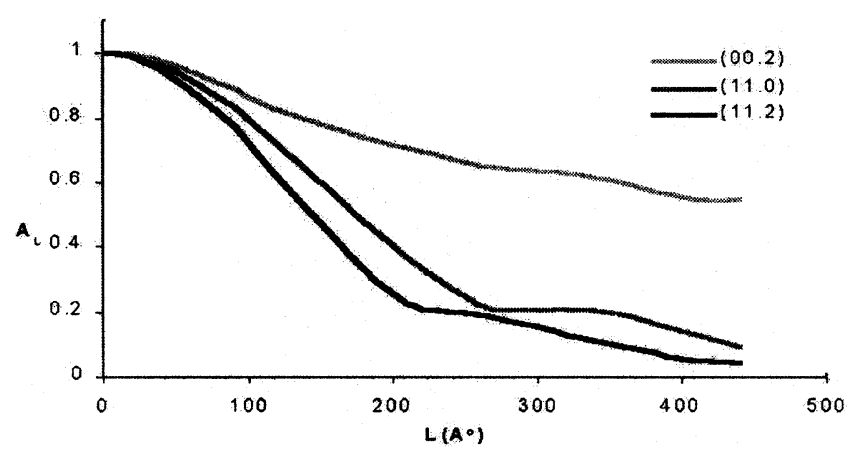

Figure 3. $A_{\mathrm{L}}$ vs $L$ plots for instrumental broadening corrected $(00 \cdot 2),(11.0)$ and $(11.2)$ peaks for the pilgered + stress relieved + annealed $\left(450^{\circ} \mathrm{C}, 3 \mathrm{~h}\right)$ sample.

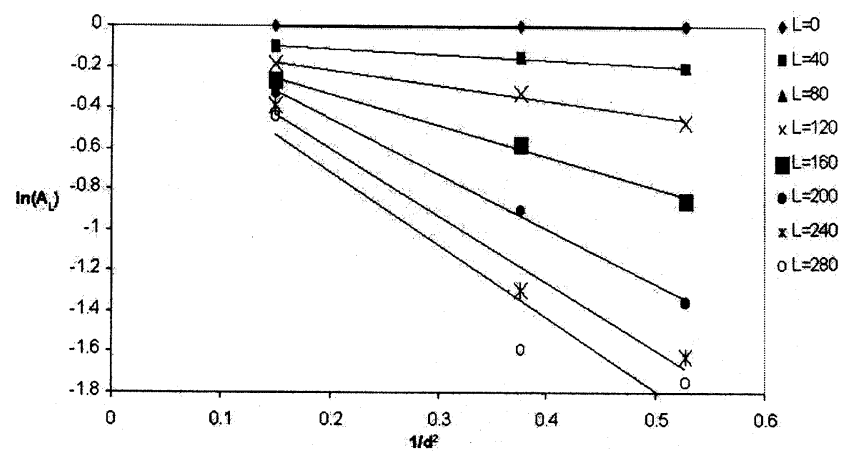

Figure 4. $\ln \left(A_{\mathrm{L}}\right)$ vs $1 / d^{2}$ plots of $H-K=3 N$ reflections for the pilgered + stress relieved + annealed $\left(450^{\circ} \mathrm{C}, 3 \mathrm{~h}\right)$ sample at different $L$ values ranging from 0 to $280 \AA$.

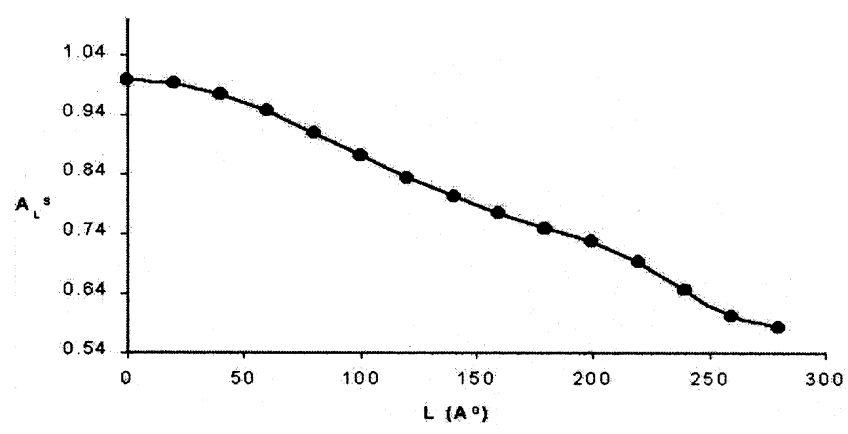

Figure 5. $A_{\mathrm{L}}^{\mathrm{S}}$ vs $L$ plots of $H-K=3 N$ reflections for the pilgered + stress relieved + annealed $\left(450^{\circ} \mathrm{C}, 3 \mathrm{~h}\right)$ sample. 
Table 5. Results of the LPA using the Fourier analysis and integral breadth.

\begin{tabular}{|c|c|c|c|c|c|c|}
\hline \multirow[b]{2}{*}{ Sample description } & \multicolumn{2}{|c|}{$\begin{array}{l}\text { Coherent domain } \\
\text { size }(D \text { in } \AA)\end{array}$} & \multicolumn{2}{|c|}{ Microstrain $\left(\varepsilon_{\mathrm{L}}\right)$} & \multicolumn{2}{|c|}{$\begin{array}{l}\text { Dislocation density } \\
\left(\rho \text { in } 10^{14} \mathrm{~m} / \mathrm{m}^{3}\right)\end{array}$} \\
\hline & FA & IBA & FA & IBA & FA & IBA \\
\hline As pilgered & 251 & 274 & $0 \cdot 00245$ & $0 \cdot 0028$ & $26 \cdot 8$ & $24 \cdot 5$ \\
\hline $\begin{array}{l}\text { Pilgered + stress relieved } \\
\quad\left(400^{\circ} \mathrm{C}, 24 \mathrm{~h}\right)\end{array}$ & 583 & $\begin{array}{l}503,559 \\
540,534\end{array}$ & $0 \cdot 00198$ & $\begin{array}{l}0 \cdot 0017,0 \cdot 0018 \\
0 \cdot 0016,0 \cdot 0016\end{array}$ & $8 \cdot 8$ & $\begin{array}{l}8 \cdot 11,7 \cdot 72 \\
7 \cdot 11,7 \cdot 19\end{array}$ \\
\hline $\begin{array}{l}\text { Pilgered }+\mathrm{SR}\left(400^{\circ} \mathrm{C}, 24 \mathrm{~h}\right)+ \\
\quad \text { annealed }\left(450^{\circ} \mathrm{C}, 3 \mathrm{~h}\right)\end{array}$ & 651 & 586 & $0 \cdot 00155$ & $0 \cdot 0012$ & $6 \cdot 11$ & $4 \cdot 91$ \\
\hline $\begin{array}{l}\text { Pilgered }+\mathrm{SR}\left(400^{\circ} \mathrm{C}, 24 \mathrm{~h}\right)+ \\
\quad \text { annealed }\left(450^{\circ} \mathrm{C}, 3 \mathrm{~h}\right)\end{array}$ & - & 862 & - & $0 \cdot 0010$ & - & $2 \cdot 78$ \\
\hline
\end{tabular}

FA, Fourier analysis; IBA, integral breadth analysis.

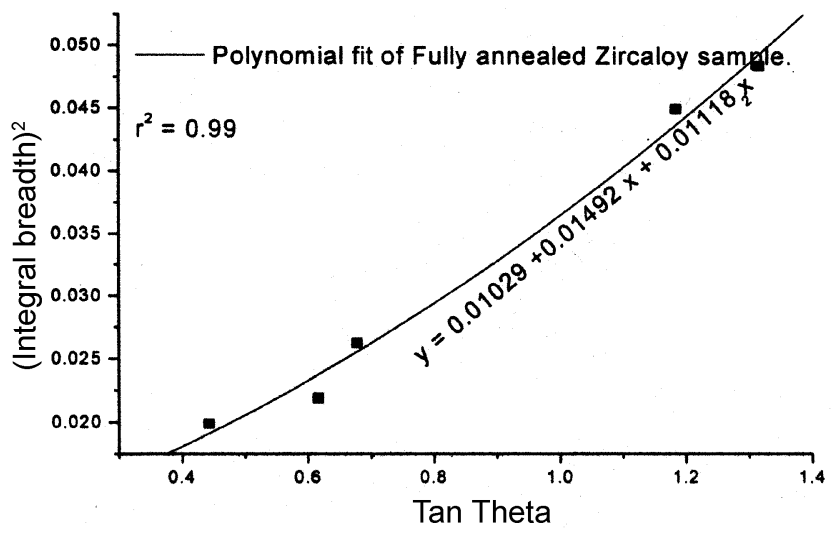

Figure 6. Fitting of curve for high intensity peaks of fully annealed zircaloy sample.

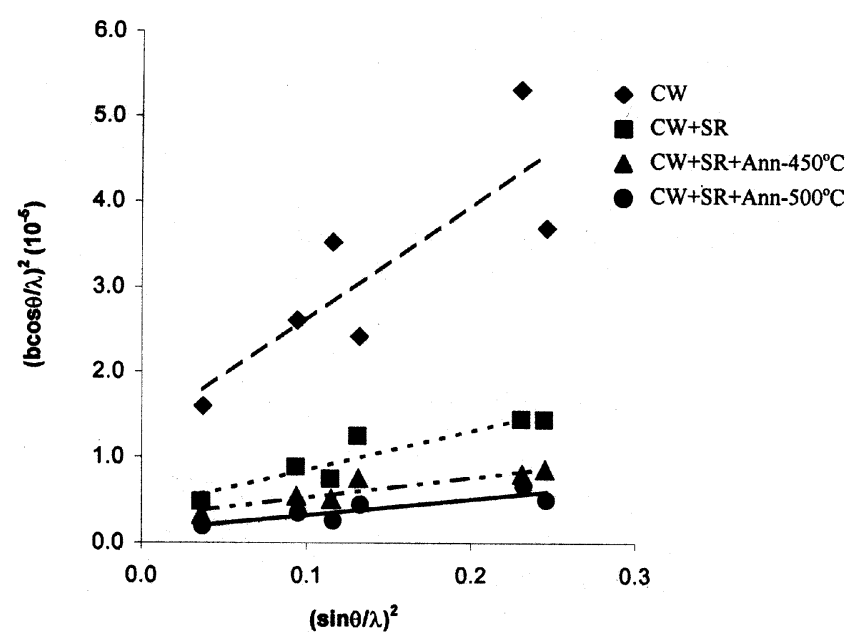

Figure 7. $(\beta \cos \theta / \lambda)^{2}$ vs $(\sin \theta / \lambda)^{2}$ plot for six high intensity peaks of cold worked, stress relieved and annealed samples.

$$
\rho_{\varepsilon}=2 k \varepsilon_{\mathrm{L}}^{2} / b^{2} \quad k=10,
$$

where $b=$ Burges vector $(a)=1 / 3[11 \overline{2} 0]$.
Dislocation density $(\rho)$ is obtained from $\rho_{D}$ and $\rho_{\varepsilon}$ as follows

$$
\rho=\left(\rho_{D} \cdot \rho_{\varepsilon}\right)^{1 / 2}
$$

The $D, \varepsilon_{\mathrm{L}}$ and $\rho$ values for different thermomechanical treatments are reported in table 5. The variation of $D, \varepsilon$ and $\rho$ after stress relieving and annealing the cold worked material is shown in figures $8 \mathrm{a}-\mathrm{c}$.

\subsection{Integral breadth analysis}

The correction for instrumental broadening $(b)$ is most important step in the estimation of material properties from line profile analysis. Integral breadth $(b)$ due to instrumental broadening is defined as ratio of the area under the peak $(A)$ and the maximum intensity $\left(I_{0}\right)$ when the sample is free from the microstructural broadening effects. The instrumental broadening $(b)$ is a function of Bragg's diffraction angle, $\theta$, (Caglioti et al 1958).

$$
(b)^{2}=U \tan ^{2} \theta+V \tan \theta+W .
$$

This model does not include the axial divergence at small angles. In our case the higher broadening at small angles was observed due to this effect. Hence small diffraction angles ( $2 \theta$ less than $30^{\circ}$ ) were excluded from the calculation.

Once the instrumental broadening is determined it has to be fitted in the above equation to get degree of fit. Various samples were used for calculation of instrumental broadening as suggested in literature, for example, annealed powder zirconium, crystal bar zirconium, CW and fully annealed zircaloy sheet etc. Best fit was obtained using a fully annealed zircaloy sheet specimen. Using high intensity peaks a curve with $Y$-axis as (integral breadth) ${ }^{2}$ and $X$-axis as $\tan \theta$ was obtained (figure 6 ). The fit was done using second order polynomial for $\tan \theta$ ( $X$-axis) and yielded the following equation for instrumental broadening 

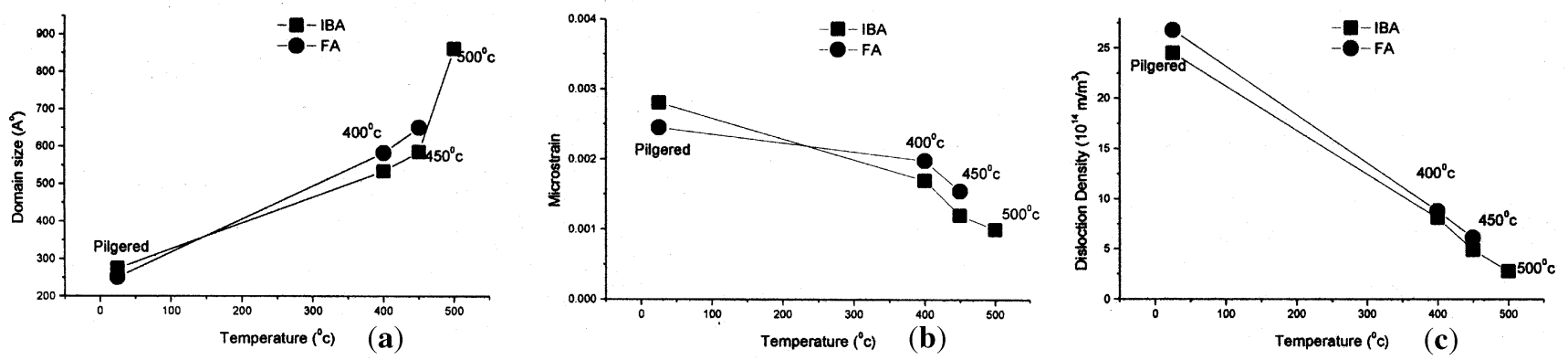

Figure 8. Comparison of (a) $D$, (b) $\varepsilon$ and (c) $\rho$ values determined using different analysis procedures.

Table 6. Comparison of the results of present study with published ones.

\begin{tabular}{llcccc}
\hline Sample & \multicolumn{1}{c}{ Source } & Technique & $D(\AA)$ & $\varepsilon$ & $\rho\left(\mathrm{m} / \mathrm{m}^{3}\right)$ \\
\hline $\mathrm{Zr}-2 \cdot 5 \mathrm{Nb} \mathrm{CWSR}\left(400^{\circ} \mathrm{C} / 24 \mathrm{~h}\right)$ & Cheadle $(1982)$ & X-ray & - & - & 5 to $7 \times 10^{14}$ \\
$\mathrm{Zr}-2 \cdot 5 \mathrm{Nb} \mathrm{CWSR}\left(400^{\circ} \mathrm{C} / 24 \mathrm{~h}\right)$ & Srivastava and Banerjee $(1992)$ & TEM & - & - & 1 to $5 \times 10^{14}$ \\
$\mathrm{Zr}-2 \cdot 5 \mathrm{Nb} \mathrm{CWSR}\left(400^{\circ} \mathrm{C} / 2 \mathrm{~h}\right)$ & Holt $(1976)$ & X-ray & 600 & - & $8 \times 10^{14}$ \\
$\mathrm{Zr}-2 \cdot 5 \mathrm{Nb} \mathrm{CW}(20 \%)$ & Holt $(1976)$ & X-ray & - & - & $17 \times 10^{14}$ \\
$\mathrm{Zr}$ powder CW annealed $\left(550^{\circ} / 18 \mathrm{~h}\right)$ & Chatterjee and Sengupta $(1974)$ & X-ray & 500 & $0 \cdot 0007$ & - \\
$\mathrm{Zr}-2 \cdot 5 \mathrm{Nb} \mathrm{CW} \mathrm{(as} \mathrm{pilgered)}$ & Present study & X-ray & 274 & $0 \cdot 0028$ & $24 \cdot 5 \times 10^{14}$ \\
$\mathrm{Zr}-2 \cdot 5 \mathrm{Nb} \mathrm{CWSR}\left(400^{\circ} \mathrm{C} / 24 \mathrm{~h}\right)$ & Present study & X-ray & 534 & $0 \cdot 0017$ & $7 \cdot 5 \times 10^{14}$ \\
\hline
\end{tabular}

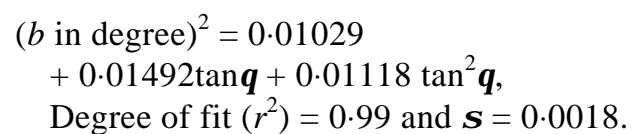

The high degree of fit ensures correct correction due to instrumental effects. The above equation was used for calculating instrumental broadening $(b)$ at any given $\theta$.

The observed integral breadth $(B)$ in the sample (for measurement of $D, \rho$ and $\varepsilon$ ) is corrected for instrumental broadening $(b)$ to give corrected integral breadth $(\beta)$ using the following relationship (Rama Rao and Anantharaman 1963).

$$
\beta=B-\left(b^{2} / B\right) .
$$

This correction assumes that the peak shape is somewhat between Gaussian and Cauchy (Lorentzian) that leads to more exact results.

The broadening in X-ray line consists of contributions due to $D$ and $\varepsilon$. Following relationship is used to separate the contributions from each of them for further calculation of $\rho$ (Sharp et al 1965).

$$
(\beta \cos \theta / \lambda)^{2}=(1 / D)^{2}+(4 \varepsilon \sin \theta / \lambda)^{2},
$$

where $\beta=$ instrumental corrected broadening (expressed in radians), $\theta=$ Bragg's diffraction angle, $D=$ coherent domain size $(\AA), \varepsilon=$ micro strain and $\lambda=$ wave length ( $)$.

The peak data is obtained using the same settings as in Fourier analysis. At least 6 peaks of high intensity between $2 \theta=34$ to $99^{\circ}$ were taken and plots of $(\beta \cos \theta / \lambda)^{2}$ vs $(\sin \theta / \lambda)^{2}$ (figure 7) were obtained. From the plots, $D$ and $\varepsilon$ were calculated using the following equations

$$
\begin{aligned}
& \text { intercept }=1 / D^{2}, \\
& \text { slope }=16 \varepsilon^{2} .
\end{aligned}
$$

Dislocation density can be calculated from $D$ and $\varepsilon$ using (10), (11) and (12) mentioned earlier.

\section{Discussion}

The variation of $D, \varepsilon$ and $\rho$ after stress relieving and annealing the cold worked material is shown in figures $8 \mathrm{a}-\mathrm{c}$. The results of the two techniques used are well in agreement with each other. While in case of integral breadth method 6 different peaks were used. In this method the effect of domain size, microstrain and stacking fault on broadening of these peaks is included. In case of the fourier analysis, only fault unaffected peaks i.e. those satisfying the criteria $H-K=3 n(9)$, were taken. Hence the calculated domain size using the fourier analysis does not include the effect of stacking faults. The observation that the domain size calculated from the two methods is similar implies that the stacking fault probability in this material is extremely low. These observations are in line with the observations of Mukerjee et al (2000).

The reported results in literature on similar conditions for this material are tabulated in table 6. The results of Xrays are in good agreement with TEM. The direct observation transmission electron microscopy (TEM) technique 
has also been used for these measurements. This technique requires preparation of thin foil which is time consuming and expensive. In contrast the X-ray methods can be used most effectively where large number of measurements are required with minimum sample preparation, like assessment of irradiation damage during the post irradiation examination of the reactor components.

The results obtained from the tensile tests on sample numbers 1 to 4 are reported in table 7 . The modified relationship between the $\mathrm{YS}$ in $\mathrm{Zr} 2.5 \mathrm{Nb}$ material and the dislocation density is as follows (Holt 1976)

$$
\sigma_{\mathrm{y}}=\sigma_{0}+\sigma_{\mathrm{Nb}}+m \alpha G b \sqrt{ } \rho
$$

where $\sigma_{\mathrm{y}}$ is yield stress, $\sigma_{0}$ the yield stress at zero dislocation density for pure zirconium of a given grain size, $\sigma_{\mathrm{Nb}}$ the solution strengthening effect due to niobium, $m$ an orientation parameter, $\alpha$ the geometric factor, $G$ the shear modulus, $b$ the Burger's vector of the $\langle a\rangle$ dislocation and $\rho$ the dislocation density.

Using the experimental data for the dislocation density and the YS measured at $573 \mathrm{~K}$ (table 7), an empirical relationship has been derived by plotting a curve between YS and $\sqrt{ } \rho$ (figure 9).

$$
\begin{aligned}
\mathrm{YS} \text { in } \mathrm{MPa}(\text { at } 573 \mathrm{~K})= & 4.963 \times 10^{-6} * \sqrt{ } \rho \\
& \left(\text { in } 1 / \mathrm{m}^{2}\right)+274.54,
\end{aligned}
$$

\section{Coefficient of correlation $\left(r^{2}\right)$ being $0 \cdot 94$.}

Using the above equation the YS has been calculated and tabulated in table 7 . The calculated results using the dislocation density data are found in very good agreement with the measured results.

The slope and the intercept of (18) can be calculated from the data on $\sigma_{0}, \sigma_{\mathrm{Nb}}, m, \alpha, G$, and $b$ available in the literature. The yield stress $\left(\sigma_{0}\right)$ of fully annealed sponge zirconium at $573 \mathrm{~K}$ is $230 \mathrm{MPa}$ with grain size of $0.7 \mu \mathrm{m}$ (Coleman and Hardie 1966). It is observed that the strengthening effect of niobium in zirconium levels off at $0.4 \mathrm{wt} \% \mathrm{Nb}$, the additional strengthening due to addition

Table 7. Measured yield strength (YS) at $573 \mathrm{~K}$ and calculated YS from (18) for samples 1 to 4.

\begin{tabular}{llcc}
\hline $\begin{array}{l}\text { Sample } \\
\text { no. }\end{array}$ & Sample description & $\begin{array}{c}\text { Measured } \\
\text { YS }(\mathrm{MPa})\end{array}$ & $\begin{array}{c}\text { Calculated } \\
\text { YS (MPa) }\end{array}$ \\
\hline 1 & $\begin{array}{l}\text { As pilgered } \\
\text { Pilgered }+ \text { stress relieved } \\
\left(400^{\circ} \mathrm{C}, 24 \mathrm{~h}\right)\end{array}$ & 523 & 531 \\
2 & $\begin{array}{l}\text { Pilgered }+ \text { SR }\left(400^{\circ} \mathrm{C}, 24 \mathrm{~h}\right)+ \\
\text { annealed }\left(450^{\circ} \mathrm{C}, 3 \mathrm{~h}\right)\end{array}$ & 410 \\
3 & $\begin{array}{l}\text { Pilgered }+\mathrm{SR}\left(400^{\circ} \mathrm{C}, 24 \mathrm{~h}\right)+ \\
\text { annealed }\left(500^{\circ} \mathrm{C}, 3 \mathrm{~h}\right)\end{array}$ & 384 \\
4 & 334 & 357 \\
\hline
\end{tabular}

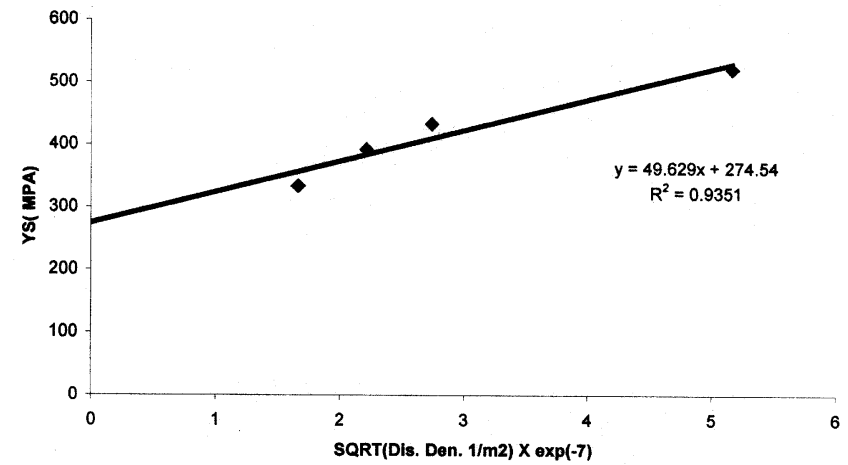

Figure 9. Plot of measured yield strength and square root (dislocation density) showing linear relationship with high degree of fit for the samples 1 to 4 .

of $\mathrm{Nb}$ has been calculated from room temperature to $775 \mathrm{~K}$ (Douglass 1963). $\sigma_{\mathrm{Nb}}=45 \mathrm{MPa}$ has been obtained by interpolation at $573 \mathrm{~K} . m$ can be taken as 2 after Aqua and Owens (1967), $\alpha$ can be taken as 0.28 after Aqua and Owens (1967), $G$ be taken as $27 \mathrm{GPa}$ at $573 \mathrm{~K}$ after Northwood et al (1975), $b$ can be taken as $3 \cdot 231 \AA$.

The slope of the curve calculated from the data in literature is $4.88 \times 10^{-6}$ (i.e. $\left.m \alpha \mathrm{Gb}\right)$ and the intercept $\left(\sigma_{0}+\right.$ $\left.\sigma_{\mathrm{Nb}}\right)$ as 275 which is very close to that obtained in the empirical relationship. Thus using this relationship the YS of the material at $573 \mathrm{~K}$ can be obtained if the dislocation density is known.

\section{Conclusions}

(I) Techniques using X-ray line broadening analysis have been used for measurement of coherent domain size, microstrain and dislocation density for the $\mathrm{Zr}-2.5 \% \mathrm{Nb}$ pressure tubes, a critical structural material for the $500 \mathrm{MW}$ nuclear PHWR.

(II) Data on $D, \varepsilon$ and $\rho$ obtained by $\mathrm{X}$-ray is consistent with the reported data using TEM methods.

(III) There is a progressive increase in the coherent domain size and decrease in microstrain and dislocation density with higher annealing temperature.

(IV) YS of the material is proportional to square root of its dislocation density. An empirical relationship has been obtained for the YS to be calculated from the dislocation density. On four samples with different heat treatments, the measured YS and the calculated YS from the dislocation density are in agreement.

\section{Acknowledgements}

The authors gratefully acknowledge the keen interest taken during the work by Dr C Ganguly, NFC, Hyderabad. 


\section{References}

Aqua E M and Owens C M 1967 Trans. Met. Soc. AIME 239 155

Caglioti G, Paoletti A and Ricci F P 1958 Nucl. Instrum. Meth. 3223

Chatterjee S K and Sengupta S P 1974 J. Mater. Sci. 9953

Cheadle B A 1982 Nucl. Technol. 57231

Coleman C E and Hardie D 1966 J.I.M. 94387

Douglass D L 1963 J. Nucl. Mater. 9252

Einarsson B 1972 Information Processings 711346

Holt R A 1976 J. Nucl. Mater. 59234

Keijser Th H, De Langford D I, Mittemeijer E J and Vogels A B P 1982 J. Appl. Cryst. 15308
Mukherjee P, Chattopadhyay S K, Chatterjee S K, Meikap A K, Barat P, Bandopadhyay S K, Sen P and Mitra M K 2000 Met. Trans. A31 2405

Northwood D O, Bahen L E and London I 1975 J. Nucl. Mater. 155299

Rama Rao P and Anantharaman T R 1963 Z. Metallk. 54658

Sharp J V, Makin M J and Christian J W 1965 Phys. Status Solidi 11845

Srivastava D and Banerjee S BARC Report 1992/1/011

Stokes A R 1948 Proc. Phys. Soc. (London) 61382

Wilson A J C 1962 Proc. Phys. Soc. (London) 8286

Warren B E 1968 X-ray diffraction (Reading Mass: AddisonWesley) p. 225

Wagner C N J and Aqua E N 1964 Adv. X-ray Anal. 746 